\title{
ALGORITMOS, BOLHA INFORMACIONAL E MÍDIAS SOCIAIS: DESAFIOS PARA AS ELEIÇÕES NA ERA DA SOCIEDADE DA INFORMAÇÃO
}

\author{
ALGORITHMS, FILTER BUBBLE AND SOCIAL MEDIA: CHALLENGES FOR \\ ELECTIONS IN THE INFORMATION AGE
}

\author{
Clara Bonaparte Pedrosa \\ Pontifícia Universidade Católica de Minas Gerais \\ Graduanda em Direito pela PUC Minas \\ Estagiária na Procuradoria da Fazenda Nacional no Estado de Minas Gerais (PFN/MG) \\ Belo Horizonte / Minas Gerais / Brasil \\ clarabonaparte12@gmail.com
}

José Alfredo de Oliveira Baracho Júnior
Pontifícia Universidade Católica de Minas Gerais
Mestre e Doutor em Direito pela UFMG. Pós-doutor pela Harvard Law School
Professor da graduação e do PPGD da PUC Minas. Advogado.
Belo Horizonte / Minas Gerais / Brasil
josealfredo@oliveirabarachoegodoi.com.br

Resumo: O uso constante das mídias sociais pelos eleitores tem como consequência a interferência destas no processo eleitoral por meio dos algoritmos, ocasionando uma bolha informacional. Essa bolha informacional faz com que notícias que deveriam chegar de forma neutra aos eleitores sejam contornadas por algoritmos, que fazem com que apenas notícias que estão de acordo com a predileção dos internautas sejam aparentes para os usuários. Por meio do método de procedimento hipotéticodedutivo, com abordagem qualitativa e técnica de pesquisa bibliográfica, concluiu-se que os algoritmos e a bolha informacional prejudicam a liberdade de informação, na medida em que esse direito é inerente a divulgação de informações diversas e difusas a todos os envolvidos no curso das eleições. Ademais, uma legislação específica, como a pretendida pelo PL 4120/2020 sobre o tema mostra-se necessária.

Palavras-chave: eleições; bolha informacional; sociedade da informação.

Abstract: The constant use of social media by voters results in interferences in the electoral process through algorithms, which creates a filter bubble. This bubble causes news to be bypassed by algorithms rather than reaching voters in a neutral manner, what leads to only news that are in line with the users' predilection being exposed to them. Through the hypothetico-deductive method, in conjunction with a qualitative and a bibliographic research, it was concluded that the algorithms and the filter bubble harms freedom of information as an inherent right in the dissemination of diverse and diffuse information to all involved in the course of elections. In addition, a specific legislation, such as that intended by the Bill 4120/2020 on the subject, turns up to be necessary.

Keywords: elections, filter bubble, information society. 
PEDROSA, Clara Bonaparte; BARACHO JUNIOR, José Alfredo de Oliveira. Algoritmos, bolha informacional e mídias sociais: desafios para as eleições na era da sociedade da informação

\section{Introdução}

As redes sociais são importante canal de informação para os brasileiros. Conforme pesquisa realizada pelo DataSenado em 2019, $83 \%$ dos brasileiros acreditam que as redes sociais têm muita influência sobre a opinião das pessoas. Em relação à frequência com que meios de comunicação e redes sociais são usados como fonte de informação, $79 \%$ dos entrevistados recorrem ao Whatsapp, 50\% à televisão, 49\% ao Youtube, 44\% ao Facebook, 38\% a sites de notícias e $30 \%$ ao Instagram (BRASIL, 2019).

As mídias sociais dominam grande parte da atual sociedade da informação, que é marcada pelo predomínio da informação esparsa, estando presente em diversos meios digitais - principalmente nas mídias sociais - para qualquer usuário que tenha um aparelho com acesso à internet. Ocorre que a as mídias sociais são regidas por algoritmos, que fazem uso de dados dos usuários para indicarem assuntos de sua relevância, fazendo com que as mídias sociais evidenciem apenas aquilo que compactua com as preferências de seus usuários, efetivando, assim, a chamada "bolha dos filtros".

Com isso, o processo eleitoral é prejudicado a partir do momento em que sofre ataques por parte da internet. A presente pesquisa visa investigar possíveis consequências do uso de algoritmos pelas mídias sociais nas eleições, problematizando a consequente bolha dos filtros gerada pelos algoritmos e a presença constante do uso das mídias sociais como forma de alterar o curso das eleições. Tem-se como hipótese o fato de que a regulação das redes sociais, ou seja, o paternalismo no ciberespaço, pode favorecer a neutralidade nos resultados do processo eleitoral.

Serão abordados tópicos em que se disserta sobre a sociedade da informação, a internet e as eleições; algoritmos e big data; internet e comportamento eleitoral; desafios das mídias sociais no período eleitoral e, por fim, regulamentação de algoritmos.

A metodologia empreendida no trabalho buscará ter o rigor de um estudo científico, fazendo uso do método de procedimento hipotético-dedutivo, com abordagem qualitativa e técnica de pesquisa bibliográfica. Como fonte primária, serão utilizados livros e artigos brasileiros e estrangeiros que contribuam para o tema. Como fonte secundária, será utilizada a legislação brasileira. 
PEDROSA, Clara Bonaparte; BARACHO JUNIOR, José Alfredo de Oliveira. Algoritmos, bolha informacional e mídias sociais: desafios para as eleições na era da sociedade da informação

\section{Panorama da sociedade da informação e da internet}

\subsection{A sociedade da informação}

“O Grande Irmão está de olho em você.” (ORWELL, 2009, p. 39). Em 1948, George Orwell escreve "1984", uma de suas principais obras, na qual elabora a visão mais antiga da sociedade da informação. No livro, o autor aborda uma sociedade distópica em que quem detém a tirania é um partido, supervisionado pelo "Grande Irmão", que controla a vida de todos os cidadãos com o objetivo de ter poder.

A sociedade da informação atual apresenta algumas similitudes quanto a antiga sociedade de informação. O termo é usado para descrever as mudanças sociais que ocorreram na segunda metade do século XX. De acordo com Karvalics (2009), o início da sociedade da informação deu-se em 1961, ano em que o protótipo da rede de computadores que forma a base tecnológica da sociedade da informação foi construído.

O termo ainda não é usado de forma unânime, podendo ser usado diferentes expressões como sinônimo de sociedade da informação, como por exemplo sociedade pós-industrial (KARVALICS, 2006) e sociedade em rede (CASTELLS, 2003).

Na sociedade da informação, dados pessoais dos consumidores são um ativo. De acordo com Bruno Bioni (2019), a inteligência gerada pelo mercado do marketing e publicidade fez com que os dados pessoais dos cidadãos se tornem relevantes para estratégias da economia mercadológica, possibilitando um novo mercado no qual há uma economia de vigilância em que o cidadão é apenas um expectador de suas informações, as quais são usadas para promover mudanças comportamentais.

Sendo assim, a "sociedade de vigilância" também faz parte da sociedade da informação. O termo tem sua origem com Foucault (2004), em sua obra "Vigiar e Punir: História das Violência nas Prisões”, publicada originalmente em 1975. Para isso, Foucault (2004) aborda o exemplo do Panóptico para prisões, em que uma estrutura grande é erguida no meio da prisão com o objetivo de observação de todas as celas ao redor. Com o surgimento das novas tecnologias, a vigilância conforme abordada por Foucault permaneceu. Entretanto, se dá por meio da internet e a coleta de dados dos internautas. Por meio da coleta desses dados, as grandes empresas detentoras das mídias sociais têm acesso as informações dos usuários, observando seu comportamento virtual.

Pode-se dizer que sociedade da informação é marcada pelo desenvolvimento da tecnologia e o consequente surgimento da internet. Com isso, é necessária uma abordagem sobre o histórico da internet e sua influência na expansão da comunicação. 
PEDROSA, Clara Bonaparte; BARACHO JUNIOR, José Alfredo de Oliveira. Algoritmos, bolha informacional e mídias sociais: desafios para as eleições na era da sociedade da informação

\subsection{Internet e democratização da comunicação}

A internet revolucionou o modo como a comunicação é realizada. Trata-se de um mecanismo de informação e divulgação e apresenta-se como um meio de colaboração e interação entre os indivíduos e seus computadores, sem considerar a sua localização geográfica, possuindo uma rede de nível mundial. De acordo com Castells (2003), a internet surgiu em 1969, nos Estados Unidos. Entretanto, só se popularizou mundialmente em 1992.

Com a popularização da internet no Brasil, esta beneficiou completamente a sociedade no sentido de facilitar a comunicação entre longas distâncias por meio das redes sociais, aumentar o engajamento político-democrático com o acesso a população a mecanismos como notícias, possibilitar o debate - uma das máximas expressões do processo democrático - por meio das redes sociais, facilitar o acesso ao conhecimento, realizar compras online, encontrar entretenimento, etc. Durante a pandemia do COVID-19, a internet mostrou-se essencial para relações de trabalho e estudo.

Ocorre que os benefícios existem conjuntamente com os malefícios. O vício pela internet é um dos principais problemas enfrentados no século XXI. Além disso, a internet tem gerado implicações na política.

O processo crescente de fenômenos como as fake news gera efeitos na seara política. De acordo com o dicionário de Cambridge, fake news são "histórias falsas que aparentam ser notícias, difundidas na internet ou em outras mídias, usualmente criadas para influenciar vertentes políticas ou como piadas" (tradução nossa) ${ }^{1}$. As fake news podem prejudicar as eleições na medida em que disseminam notícias que geram desinformação sobre os protagonistas envolvidos no processo eleitoral. De acordo com estudo realizado pela Universidade de Oxford (2019), notícias falsas possuem um engajamento maior nas mídias sociais. Pode-se citar como exemplo o Facebook, em que as fake news podem superar em até quatro vezes o volume de compartilhamentos, curtidas e comentários (OXFORD, 2019).

Outro fenômeno são os bots, frequentemente utilizados na campanha do presidente Jair Bolsonaro nas eleições de 2018 do Brasil. Porto Junior (2018) define os bots como um mecanismo de automatização de tarefas, podendo variar conforme a sua complexidade, podendo ser desde um simples programa que realiza o compartilhamento de postagens até um assistente pessoal.

${ }^{1}$ [Original] false stories that appear to be news, spread on the internet or using other media, usually created to influence political views or as a joke. (CAMBRIGDE DICTIONARY, 2020, on-line) 
PEDROSA, Clara Bonaparte; BARACHO JUNIOR, José Alfredo de Oliveira. Algoritmos, bolha informacional e mídias sociais: desafios para as eleições na era da sociedade da informação

Sendo assim, os bots funcionam como influenciadores de votos a partir do momento em que interagem com outros usuários das mídias sociais, debatendo a favor de um candidato e podendo aumentar o número de seguidores ou curtidas de determinado político, gerando a ideia de um apoio inexistente. São projetados para parecer verdadeiros usuários, sendo de difícil distinção para estes.

Por fim, há os algoritmos, objeto deste estudo como se verá a seguir.

\section{Dos algoritmos}

\subsection{Bolha informacional e informação fragmentada nas mídias sociais}

A definição de um algoritmo não é precisa. Entretanto, para fins desse trabalho, considera-se algoritmo como "um plano de ação pré-definido a ser seguido pelo computador, de maneira que a realização contínua de pequenas tarefas simples possibilitará a realização da tarefa solicitada sem novo dispêndio de trabalho humano." (VALENTINI, 2017, p. 43). Podese citar como exemplo o algoritmo do Facebook. Ao criar uma conta no site, o usuário deve, inicialmente, relatar seus interesses em filmes, música, jogos, times de futebol, etc. Com isso, passa a curtir páginas referentes aos seus gostos. Com o tempo, o algoritmo é configurado a partir das curtidas realizadas pelo usuário em seu feed de notícias. Dessa forma, é instaurado o filtro bolha.

O filtro bolha funciona com base na mineração de dados, que é o processo de examinar grandes quantidades de dados para encontrar padrões de preferência dos usuários. Com isso, as empresas conseguem evidenciar tendências de comportamento dos usuários das mídias sociais. Essa grande quantidade de dados é denominada Big Data, que consiste na análise de um grande volume de dados dos usuários e no principal modelo de negócios das grandes empresas de tecnologia atuais. O Big Data torna possível a inferência de acontecimentos para que a publicidade das empresas de tecnologia seja direcionada.

Eli Pariser (2011), em obra pioneira, introduz o conceito de filtro bolha, afirmando que este consiste em um mecanismo que examina aquilo que os seres humanos gostam e parte dessa premissa para refinar e criar espaços que condizem com tal informação. Eduardo Magrani (2014), em sua obra "Democracia conectada: a internet como forma de engajamento políticodemocrático" define o filtro bolha como uma base de dados gerado por algoritmos em que se faz uma personificação dos conteúdos criados pelos usuários, feita pelas Big Techs.

Pode-se citar como exemplo o Google, principal mecanismo de busca do mundo, que funciona de forma seletiva. Ainda de acordo com Pariser (2011), desde dezembro de 2009, os internautas não obtêm os mesmos resultados das buscas do Google, por exemplo. A partir 
PEDROSA, Clara Bonaparte; BARACHO JUNIOR, José Alfredo de Oliveira. Algoritmos, bolha informacional e mídias sociais: desafios para as eleições na era da sociedade da informação

daquela data, os resultados das pesquisas são direcionados para cada usuário específico, sendo diferente para os outros usuários.

O filtro bolha, ou bolha dos filtros, é benéfico para o usuário a partir do momento em que mostra apenas as suas predileções. Como por exemplo no streaming Netflix, no qual é visível ao espectador somente suas séries e filmes recomendadas a partir do que este já assistiu. Ao passo que é prejudicial pelo mesmo motivo no que se refere a esfera da comunicação social, tendo em vista que muitos se informam por via das mídias sociais.

No YouTube, há evidências de que seus algoritmos manipulam os vídeos a serem assistidos. Guillaume Chaslot, ex-engenheiro de software do Youtube, em parceria com o jornal britânico The Guardian (2020), fez uma pesquisa para análise sobre uma possível preferência ideológica da plataforma. A pesquisa fez um amplo estudo de 8.052 vídeos, em que os 1.000 conteúdos mais recomendados foram analisados pelos pesquisadores.

Os pesquisadores concluíram que 643 vídeos tinham uma ideologia. Desses, 551 (86\%) favoreceram Donald Trump, enquanto apenas 92 vídeos (14\%) foram benéficos para Clinton. Com isso, o internauta encontra-se em um filtro-bolha a partir do momento em que só tem acesso majoritário a uma opção.

O filtro bolha gera informações fragmentadas, fazendo com que os usuários das mídias sociais tenham acesso apenas aquilo que compactua com a sua preferência política. A informação fragmentada é prejudicial à democracia a partir do momento em que os indivíduos estão sujeitos, sem ter consciência, a ausência de acesso a pontos de vista diferentes, empobrecendo o debate democrático e, consequentemente, gerando efeitos no voto nas eleições.

\subsection{A falta de transparência dos algoritmos}

Os meios de comunicação possuem um papel primordial na formação da opinião da sociedade. Uma pesquisa realizada pelo DataSenado (2019) aponta que a maioria dos entrevistados concorda que devem ser públicas as regras usadas pelos sites de busca e redes sociais para escolher os conteúdos exibidos para os usuários.

Algoritmos são obscuros, fazendo com que afetem a sociedade de modo que não se tem conhecimento. A ausência de neutralidade dos algoritmos se dá devido ao fato de que incorporam visões e valores dos programadores e empresas que os desenvolveram, podendo ser tendenciosos quanto ao compartilhamento de informações. 
PEDROSA, Clara Bonaparte; BARACHO JUNIOR, José Alfredo de Oliveira. Algoritmos, bolha informacional e mídias sociais: desafios para as eleições na era da sociedade da informação

Frank Pasquale (2015), autor norte-americano especialista no assunto, em sua obra The Black Box Society, afirma que decisões que deveriam ser baseadas em reflexões humanas são agora feitas automaticamente, sendo necessário que se revele o segredo dos algoritmos a fim de que os humanos não sejam influenciados pelos vieses das máquinas. Deve-se levar em consideração que, por trás dos algoritmos, há um programador, que dita aquilo que deve ser considerado relevante ou não.

As plataformas de mídias sociais moderam as comunicações por meio de dois modos, os quais consistem no controle suave (soft control) e no controle rígido (hard control). $\mathrm{O}$ controle suave refere-se aquilo que é mostrado no feed de notícias dos usuários, controlando aquilo que estes prestam atenção. Enquanto o controle rígido trata-se dos conteúdos a serem aceitos para publicação nas plataformas. Tanto o controle suave quanto o controle rígido fazem uso de algoritmos, que de forma geral também são combinados com intervenção humana por meio de mecanismos opacos aos usuários, dificultando a sua compreensão (FORNASIER, 2020).

\section{Internet e comportamento eleitoral}

Em 2016, Alexander Nix, ex-presidente da empresa Cambridge Analytica, responsável pelo escândalo de vazamento de dados dos usuários do Facebook, proferiu uma palestra sobre "O Poder do Big Data e da Psicografia" no processo eleitoral. O palestrante afirma que, apesar de já existirem modelos psicográficos de entendimento de personalidades, grande parte das empresas de comunicação ainda dividem sua audiência em dados demográficos e geográficos que apenas preveem opiniões das pessoas, de modo que não compreendem verdadeiramente o âmago da individualidade dos indivíduos (VAIDHYANATHAN, 2018).

Dessa forma, "com o uso de perfis psicográficos, um profissional de marketing ou campanha pode abordar precisamente um indivíduo", afirma Vaidhyanathan (2018, p. 151). O uso do Big Data mostra-se importante a partir do momento em que é coletado informações sobre os usuários de mídias sociais por meio de seus dados. Com isso, posts e propagandas são direcionados para estes.

O modelo psicográfico consiste em: 
[...] o perfil psicográfico usa designações de caracteres como "abertura" (quão acolhedora é uma pessoa para novas experiências), "consciência" (quanto prefere ordem e regularidade ou mudança e fluidez), "extroversão" (quão social é uma pessoa), "agradabilidade" (vontade de colocar as necessidades de outras pessoas acima das suas) e "neuroticismo" (quanto a pessoa se preocupa). Isso é conhecido no comércio como o modelo "OCEAN". (VAIDHYANATHAN, 2018, p. 151) (tradução nossa $)^{2}$

Ademais, outras estratégias de comportamento político são utilizadas pela equipe de marketing da campanha eleitoral de políticos. Essas estratégias perpassam pelas teorias de escolha do voto. Existem três explicações clássicas sobre as escolhas eleitorais: teoria sociológica, teoria psicossocial e teoria da escolha racional.

Cervi (2012) sumariza a teoria sociológica, na qual afirma que esta relaciona-se com o contexto no qual o indivíduo está inserido, e não com os aspectos individuais do ser humano. O coletivo social como o contexto institucional, as práticas, as ideologias e os objetivos políticos influenciam o voto do cidadão.

Mundin exemplifica: "Uma pessoa que nascesse numa família republicana e morasse num reduto republicano tenderia a ser republicano, seja pelas predisposições familiares, seja pela rede social em que ela estaria envolvida. O mesmo valia para os democratas." (MUNDIN, 2010, p. 343).

Nesse modelo, a mídia ocupa o papel central de influenciadora de opiniões. Ainda de acordo com Mundin (2010), a mídia pode afetar o comportamento do eleitor via relações políticas sociais, seja por meio de interação social entre os indivíduos ou por apelos momentâneos de campanha, na qual interfere de modo direto sobre as decisões dos indivíduos.

A teoria psicossocial surgiu em 1964. Os pesquisadores da escola passaram a investigar o comportamento eleitoral com a finalidade de investigar tendências comportamentais de eleitores individuais e não mais advindos dos resultados das eleições (CERVI, 2012). "A partir da análise de atributos individuais e das preferências políticas, o grupo [...] buscava na psicologia uma ligação entre a posição social e o comportamento político". (CERVI, 2012, p. 105). A teoria sociológica tornou-se obsoleta, tendo em vista que existem fatores psicológicos, como a história psicológica, que alteram comportamentos políticos. Quanto ao papel da mídia, a única menção dos autores da escola é a de que esta não possui um papel relevante na hora de $\operatorname{votar}($ MUNDIN, 2010).

\footnotetext{
2 [Original] [...] psychographic profiling uses character designations such as "openness" (how welcoming a person is to new experiences), "conscientiousness" (how much one prefers order and regularity or change and fluidity), "extroversion" (how social a person is), "agreeableness" (one's willingness to put other people's needs above her own), and "neuroticism" (how much a person worries). This is known in the trade as the "OCEAN" model. (VAIDHYANATHAN, 2018, p. 151)
} 
PEDROSA, Clara Bonaparte; BARACHO JUNIOR, José Alfredo de Oliveira. Algoritmos, bolha informacional e mídias sociais: desafios para as eleições na era da sociedade da informação

A teoria da escolha racional surgiu com Antony Downs. "Para a teoria da escolha racional, o voto é definido em função de um cálculo de custo-benefício, sendo os valores e a ideologia mais genéricos considerados quase irrelevantes para a ação eleitoral.” (CERVI, 2012, p. 113). Nesta, os indivíduos agem intencionalmente, tendo em vista que são racionais.

Sobre o papel e a influência da mídia neste modelo, Mundin (2010) afirma que as informações da imprensa geram consequências nas conversas sobre política entre os cidadãos. Por isso, é necessário que os partidos políticos, políticos ou governos façam uso dos meios de comunicação para comunicar suas realizações com o fim de gerar impacto nos diálogos corriqueiros da população.

O papel da imprensa é tão relevante que, mesmo aqueles indivíduos que não possuem interesse por política, ao assistir televisão por diversão, por exemplo, podem absorver alguma informação sobre aquele assunto, de forma indireta. Os eleitores racionais delegam a terceiros, como por exemplo colunistas e comentaristas, a responsabilidade de tomada de decisão política (MUNDIN, 2010).

Dessa forma, a mídia ocupa o papel de intermediária entre as informações e a tomada de decisão racional. Trazendo a análise para as novas tecnologias e os novos meios de comunicação social, como a internet, pode-se dizer que a teoria da escolha racional sofre consequências advindas das mídias sociais, tendo em vista que estas são fonte de informação para a maioria dos brasileiros (BRASIL, 2019). O papel dos algoritmos é de filtrar as informações, fazendo com que os internautas vivam num filtro-bolha, conforme explicitado nos tópicos anteriores. Com isso, a escolha racional do voto é prejudicada a partir do momento em que o usuário não tem acesso a todas as informações.

\section{Desafios das mídias sociais no período eleitoral}

5.1. O dever de informação dos tradicionais meios de comunicação versus dos novos meios

A mídia afeta a sociedade. A televisão teve um efeito profundo na vida política do século XX. Posteriormente, houve a advinda de novos veículos de comunicação, como a internet. A informação é um direito fundamental, estando positivada no artigo 5o, inciso XIV da Constituição brasileira de 1988: "é assegurado a todos o acesso à informação [...]" (BRASIL, 1988)

Por muito tempo os veículos tradicionais de mídia, como a televisão, jornais e revistas predominaram como fonte de informação privada. No mundo atual, muitos se informam por meio da internet, acessando jornais e revistas online ou por via de aplicativos, como o Facebook, Twitter, YouTube e Instagram. Ocorre que estes aplicativos não possuem um Código 
PEDROSA, Clara Bonaparte; BARACHO JUNIOR, José Alfredo de Oliveira. Algoritmos, bolha informacional e mídias sociais: desafios para as eleições na era da sociedade da informação

de Ética como a imprensa tradicional. No Código de Ética da imprensa tradicional há um capítulo destinado ao direito à informação.

Em um de seus artigos, especificamente o artigo $2^{\circ}$, o Código de Ética impede que a informação seja dominada por algum tipo de interesse, dispondo que o acesso à informação é de interesse público, sendo um direito fundamental. Para mais, o referido Código justifica que “a divulgação da informação precisa e correta é dever dos meios de comunicação e deve ser cumprida independentemente de sua natureza jurídica [...] e da linha política de seus proprietários e/ou diretores" (CÓDIGO DE ÉTICA DOS JORNALISTAS BRASILEIROS, 2007).

Os aplicativos ora citados, assim como os veículos tradicionais de mídia, informam e não possuem nenhum Código de Ética ou Conduta semelhante, fazendo com que sua conduta seja desregulada e a informação seja distribuída de maneira seletiva. Ademais, a Constituição brasileira de 1988, no artigo 220, parágrafo 5o, proíbe que os meios de comunicação social sejam controlados, direta ou indiretamente, por monopólio ou oligopólio, aumentando a pluralidade de opções de informação.

Pode-se dizer que os tradicionais veículos de comunicação, de forma anterior ao surgimento dos algoritmos, funcionavam por meio da seleção dos leitores ou espectadores por determinados jornais ou canais de televisão. Assim, por exemplo, um indivíduo de posição política conservadora direita só lia jornais conservadores e só assistia canais conservadores. Entretanto, estes veículos antigos de mídia, por obrigatoriedade, contavam com notícias de outra opção de preferência política, ainda que ínfimas.

A democracia está intrinsecamente ligada ao direito à informação na medida que, enquanto sistema de governo baseado na participação popular e no pluralismo de ideias, necessita da informação para que os cidadãos tenham conhecimento para participar da tomada de decisões. A liberdade de informação tem compromisso com a verdade.

\subsection{O processo eleitoral brasileiro}

O processo eleitoral brasileiro está disciplinado pelo Código Eleitoral (Lei n. 4.737/1965). Há também a Lei Eleitoral (Lei n. 9.504/1997), que estabelece normas para as eleições.

A Lei Eleitoral (1997), em seu artigo 57-B e 57-C, disciplina a propaganda na internet, a qual dispõe que a propaganda eleitoral poderá ser realizada por meio de "blogs, redes sociais, sítios de mensagens instantâneas e aplicações de internet assemelhadas cujo conteúdo seja 
PEDROSA, Clara Bonaparte; BARACHO JUNIOR, José Alfredo de Oliveira. Algoritmos, bolha informacional e mídias sociais: desafios para as eleições na era da sociedade da informação

gerado ou editado por candidatos, partidos ou coligações ou qualquer pessoa natural, desde que não contrate impulsionamento de conteúdos” (BRASIL, 1997).

A referida Lei Eleitoral (1997), em seu artigo 57-C, ainda dispõe que é possível o impulsionamento de conteúdos na internet nos casos em que seja identificado "de forma inequívoca como tal e contratado exclusivamente por partidos, coligações e candidatos e seus representantes" (BRASIL, 1997).

Para as eleições de 2018, a reforma eleitoral de 2017 alterou a Lei Eleitoral e passou a admitir totalmente o impulsionamento de conteúdo. Um exemplo de impulsionamento seria a exibição de anúncios de campanha no feed de notícias do Facebook de internautas advindos do perfil de determinado candidato. Este fato aumenta a bolha informacional dos eleitores, visto que só será impulsionado aquilo que condiz com suas preferências políticas.

Além disso, a Lei Eleitoral dispõe sobre a liberdade de expressão em seu artigo 57-D, dispondo que a manifestação do pensamento por meio da rede mundial de computadores é livre, sendo vedado o anonimato em época de campanha eleitoral e sendo assegurado o direito de resposta (BRASIL, 1997).

A liberdade de expressão é essencial para a manutenção da democracia e das eleições a partir do momento em que assegura o livre fluxo de ideias e a formação de um debate público, sendo essencial para a tomada das decisões. Ocorre que não há liberdade de expressão com a política algorítmica que dita aquilo que deve ser visto e informado.

\section{Devem regular os algoritmos?}

\subsection{O uso de dados pessoais para fins eleitorais}

Nas eleições de 2012, a equipe de marketing do ex-presidente dos Estados Unidos, Barack Obama, baseou sua estratégia de campanha eleitoral em informações geradas por pesquisas e ferramentas de Big Data, direcionando aos diferentes tipos de eleitores (principalmente os indecisos) informações sobre suas pretensões. As redes sociais mostraramse importantes ambientes de coleta de informações digitais para formar bancos de dados.

O Big Data revolucionou o modo de realizar estratégicas políticas, favorecendo uma segmentação mais precisa dos eleitores se comparado as estratégias tradicionais. A equipe responsável pelas eleições norte-americanas que teve como eleito o referido ex-presidente, fez com que fosse identificado o perfil do eleitor indeciso por meio de pesquisas diárias, tendo informações como o que iria persuadi-lo, facilitando a tomada de decisões (ANTONIUTTI; ALBAGLI, 2014). 
PEDROSA, Clara Bonaparte; BARACHO JUNIOR, José Alfredo de Oliveira. Algoritmos, bolha informacional e mídias sociais: desafios para as eleições na era da sociedade da

informação

Em 2016, foi a vez do presidente dos Estados Unidos, Donald Trump, fazer uso das novas tecnologias para alavancar sua campanha eleitoral. A questão teve sua origem em 2014, quando o aplicativo ThisIsYourDigitalLife coletava dados dos usuários do Facebook por meio de um questionário. Com isso, o mecanismo captou informações pessoais de 87 milhões de usuários do Facebook. Este aplicativo repassou suas informações para a Cambridge Analytica, uma empresa de estratégia eleitoral. Dessa forma, a empresa teria conhecimento acerca de cada usuário, podendo direcionar anúncios e notícias. "Fornecer a informação certa à pessoa certa, no momento certo é mais importante do que nunca", afirma uma propaganda da Cambridge Analytica $^{3}$

Vaidhyanathan explica o fenômeno da candidatura de Trump:

\begin{abstract}
Uma coisa ficou clara e a campanha de Trump foi direta: o Facebook fez a diferença. Isso permitiu que Trump visasse anúncios a eleitores em estados selecionados com uma precisão notável. Em alguns casos, os anúncios do Facebook foram feitos para dissuadir potenciais eleitores de Clinton. Em outros, a equipe de Trump adaptou e testou cuidadosamente os anúncios do Facebook para motivar pequenos segmentos de potenciais eleitores de Trump, para que eles apareçam nas pesquisas. Funcionou. $\mathrm{O}$ Facebook acabou sendo uma ferramenta mais poderosa nas mãos de Trump do que jamais havia sido para candidatos supostamente experientes em tecnologia, como o presidente Barack Obama. (VAIDHYANATHAN, 2018, p. 149) (tradução nossa) ${ }^{4}$
\end{abstract}

No Brasil, a Lei Eleitoral (1997) dispõe que a responsabilidade pela divulgação indevida de dados pessoais para fins eleitorais cabe ao provedor de conteúdo. Em seu artigo 57F, a referida Lei explicita que "aplicam-se ao provedor de conteúdo e de serviços multimídia que hospeda a divulgação da propaganda eleitoral de candidato, de partido ou de coligação as penalidades previstas nesta Lei se [...] não tomar providências para a cessação dessa divulgação" (BRASIL, 1997).

Para mais, a Lei Eleitoral afirma que o provedor de conteúdo ou de serviços multimídia responsabiliza-se pela divulgação da propaganda somente se a postagem do conteúdo for, de forma comprovada, de seu prévio conhecimento (BRASIL, 1997). Dessa forma, a responsabilidade recai juridicamente sobre as mídias sociais.

\footnotetext{
${ }^{3}$ ENTENDA o escândalo de uso político de dados que derrubou valor do Facebook e o colocou na mira de autoridades. G1, 20 de março de 2018. Disponível em: <https://g1.globo.com/economia/tecnologia/noticia/entenda-o-escandalo-de-uso-politico-de-dados-que-derrubouvalor-do-facebook-e-o-colocou-na-mira-de-autoridades.ghtml>. Acesso em 11 de ago. 2020

${ }^{4}$ [Original] One thing became clear, and the Trump campaign was blunt about it: Facebook made a difference. It allowed Trump to target advertisements at voters in select states with remarkable precision. In some cases, Facebook ads were meant to dissuade potential Clinton voters. In others, the Trump team carefully tailored and tested Facebook ads to motivate small segments of potential Trump voters so they might show up at the polls. It worked. Facebook turned out to be a more powerful tool in the hands of Trump than it had ever been for allegedly technologically savvy candidates such as President Barack Obama. (VAIDHYANATHAN, 2018, p. 149)
} 
PEDROSA, Clara Bonaparte; BARACHO JUNIOR, José Alfredo de Oliveira. Algoritmos, bolha informacional e mídias sociais: desafios para as eleições na era da sociedade da informação

\title{
6.2. Privacidade e proteção de dados
}

No Brasil, a proteção de dados pessoais encontra respaldo legal na Lei n. 13.709/2018, conhecida como Lei Geral de Proteção de Dados Pessoais (LGPD). A Lei Geral de Proteção de Dados trouxe uma gama de novas definições para o direito brasileiro, destacando-se os dados pessoais e os dados pessoais sensíveis:

\begin{abstract}
Art. $5^{\circ}$ Para os fins desta Lei, considera-se:
I - dado pessoal: informação relacionada a pessoa natural identificada ou identificável;

II - dado pessoal sensível: dado pessoal sobre origem racial ou étnica, convicção religiosa, opinião política, filiação a sindicato ou a organização de caráter religioso, filosófico ou político, dado referente à saúde ou à vida sexual, dado genético ou biométrico, quando vinculado a uma pessoa natural; (BRASIL, 2018).
\end{abstract}

A opinião política configura-se como um dado pessoal sensível. Dessa forma, a Lei Geral de Proteção de Dados estabelece um regime específico para este tipo de dados, sendo seu processamento proibido ${ }^{5}$. A regulamentação quanto aos dados das opiniões políticas faz-se necessária a partir do momento em que os algoritmos fazem uso desses dados para obter conhecimento acerca das preferências políticas dos usuários das mídias sociais, direcionando informações selecionadas especificamente para estes.

A Lei Geral de Proteção de Dados pode favorecer o processo eleitoral a partir do momento em que regulamenta como os dados devem ser usados pelos algoritmos. Ademais, em seu artigo 20, esta garante o direito à explicação de decisões automatizadas, afirmando que o titular dos dados tem direito à explicação das decisões automatizadas que contaram com o uso automatizado de seus dados pessoais, desde que tenham atingido sua esfera pessoal (BRASIL, 2018).

A LGPD ainda afirma que "o controlador deverá fornecer, sempre que solicitadas, informações claras e adequadas a respeito dos critérios e dos procedimentos utilizados para a decisão automatizada, observados os segredos comercial e industrial” (BRASIL, 2018). A penalidade consiste na interferência da Autoridade Nacional de Proteção de Dados, que poderá realizar auditoria para investigar o uso de decisões automatizadas (BRASIL, 2018).

\footnotetext{
${ }^{5}$ Exceto nos casos de: existir o expresso consentimento do titular do dado ou de seu responsável legal, para finalidades específicas; o processamento seja necessário para cumprimento de obrigação legal ou regulatória pelo controlador; o processamento seja necessário por razões de substancial interesse público, desde que as políticas públicas estejam previstas em lei ou regulamento; o processamento seja necessário em razão de interesse público na pesquisa científica, história ou estatística; o processamento seja para exercício regular de direitos, em nível extrajudicial ou judicial; o processamento seja necessário em razão de interesse público na área da saúde, inclusive para a proteção da vida e da incolumidade física do titular; ou o processamento seja necessário para garantia da prevenção à fraude e a segurança do titular. (SIQUEIRA, 2019, p. 19)
} 
PEDROSA, Clara Bonaparte; BARACHO JUNIOR, José Alfredo de Oliveira. Algoritmos, bolha informacional e mídias sociais: desafios para as eleições na era da sociedade da informação

Decisões automatizadas são decisões tomadas por algoritmos. De acordo com Becker e Rodrigues (2019, p. 129), "o direito à explicação surge da necessidade de resolver o problema da opacidade da tomada de decisões automatizadas e das graves consequências sociais comumente ocasionadas por suas falhas".

\subsection{O projeto de lei $n .4120 / 2020$}

No dia 07 de agosto de 2020, o deputado Bosco Costa (PL/SE), apresentou o requerimento n. 2108/2020 e o projeto de lei n. 4120/2020, que "Disciplina o uso de algoritmos pelas plataformas digitais na internet, assegurando transparência no uso das ferramentas computacionais que possam induzir a tomada de decisão ou atuar sobre as preferências dos usuários." (BRASIL, 2020).

O projeto de lei tem como justificativa a obscuridade dos algoritmos, visto que não há consenso sobre as questões relativas ao seu funcionamento, apesar de que existem estudos que mostram que os dados pessoais dos usuários interferem em seu funcionamento (PASQUALE, 2015). Entretanto, devido à total obscuridade do processamento das plataformas, este fato não pode ser confirmado.

Ademais, o autor justifica o PL com base nas distorções de casos envolvendo manipulação por parte dos vieses algorítmicos e no caso já abordado neste texto, Cambridge Analytica. Este ainda afirma que já existem legislações sobre o tema em outros países, como na França, com a Lei n. 1321/16 e o projeto de lei norte-americano chamado "Lei da Responsabilidade Algorítmica”, no qual "o intuito da proposta é autorizar as autoridades daquele país a realizar avaliações periódicas do impacto dos sistemas de decisão automatizada utilizados pelas grandes plataformas digitais na internet” (BRASIL, 2020).

\section{Conclusões}

O advento da internet gerou uma nova cultura no mundo, em que é necessário que a sociedade, agora chamada sociedade da informação, se adapte a esta. Não só a sociedade deve se adaptar, bem como fatores como, por exemplo, as eleições, objeto desse estudo, devem se encaixar nas mudanças do novo mundo. Como vimos, as eleições têm sido afetadas pelas mídias sociais, especificamente quanto aos algoritmos e suas bolhas informacionais.

Os algoritmos e a bolha dos filtros interferem na liberdade de informação dos usuários a partir do momento em que estas impedem que os internautas alcancem todas as informações possíveis dentro de um círculo constantemente acessado por estes. Ademais, a teoria da escolha 
PEDROSA, Clara Bonaparte; BARACHO JUNIOR, José Alfredo de Oliveira. Algoritmos, bolha informacional e mídias sociais: desafios para as eleições na era da sociedade da informação

racional mostra que os eleitores escolhem seus votos de acordo com a exposição da mídia. Dessa forma, como a liberdade de informação abarca o direito de ser informado de forma difusa, é necessário que a bolha informacional seja extinta.

Uma alternativa elencada aos algoritmos e a bolha informacional, como vimos, é elencada pela Lei Geral de Proteção de Dados. Como os algoritmos necessitam ser alimentados por uma base de dados para seu funcionamento, a Lei, que protege os dados dos eleitores, é de bastante utilidade, visto que a bolha informacional seria passível de menor espaço para a sua existência.

Outra alternativa é a legislação específica para a regulação de algoritmos e bolhas informacionais, com o projeto de lei 4120/2020 propõe. Apesar de já existir legislação para o microdirecionamento no processo eleitoral brasileiro, outro tipo de paternalismo no ciberespaço mostra-se, às vezes, necessário. Uma lei - como a pretendida pelo PL 4120/2020 - que elenque aspectos como princípios e fundamentos para uso dos algoritmos na internet, bem como regras para sua aplicação, seria de enorme benefício para dissipar os desafios para as eleições na sociedade da informação.

\section{Referências}

BIONI, Bruno Ricardo. Proteção de Dados Pessoais: a função e os limites do consentimento. Rio de Janeiro: Forense, 2019.

BRASIL. Constituição (1988). Constituição da República Federativa do Brasil de 1988. Disponível em:http://www.planalto.gov.br/ccivil_03/constituicao/constituicao.htm. Acesso em: 11 de agosto de 2020 .

BRASIL. DATASENADO. . Redes Sociais, Notícias Falsas e Privacidade de Dados na Internet. Brasília: Congresso Nacional, 2019. Disponível em: https://www12.senado.leg.br/institucional/datasenado/arquivos/mais-de-80-dos-brasileirosacreditam-que-redes-sociais-influenciam-muito-a-opiniao-das-pessoas. Acesso em: 11 ago. 2020 .

BRASIL. Lei $\mathrm{n}^{\circ}$ 9.504, de 30 de setembro de 1997. Estabelece normas para as eleições.. . Brasília, 30 set. 1997. Disponível em: http://www.planalto.gov.br/ccivil_03/leis/19504.htm\#: :text=LEI\%20N\%C2\%BA\%209.504\% 2C\%20DE\% 2030\%20DE\%20SETEMBRO\%20DE\%201997.\&text=Estabelece\%20normas\% 20para\%20as\%20elei\%C3\%A7\%C3\%B5es. Acesso em: 11 ago. 2020.

BRASIL. Lei n. 13.709, de 14 de agosto de 2018. Lei Geral de Proteção de Dados Pessoais (LGPD). Diário Oficial da União. Disponível em: http://www.planalto.gov.br/ccivil_03/_ato2015-2018/2018/lei/L13709.htm. Acesso em: 11 de ago. de 2020. 
PEDROSA, Clara Bonaparte; BARACHO JUNIOR, José Alfredo de Oliveira. Algoritmos, bolha informacional e mídias sociais: desafios para as eleições na era da sociedade da informação

BRASÍLIA. Câmara dos deputados. Projeto de Lei PL 4120/2020. Disciplina o uso de algoritmos pelas plataformas digitais na internet, assegurando transparência no uso das ferramentas computacionais que possam induzir a tomada de decisão ou atuar sobre as preferências dos usuários. Disponível em: https://www.camara.leg.br/propostaslegislativas/2259721. Acesso em 13 ago. 2020. Texto original.

CASTELLS, Manuel. A galáxia da internet: reflexões sobre a internet, os negócios e a sociedade. 1. ed. Rio de Janeiro: Zahar, 2003.

CERVI, Emerson. Opinião pública e comportamento eleitoral. Curitiba: Ibpex, 2010. DICTIONARY, Cambridge. Fake News. Inglaterra: Cambridge Dictionary, 2020. Disponível em: https://dictionary.cambridge.org/pt/dicionario/ingles/fake-news. Acesso em: 11 ago. 2020

ENTENDA o escândalo de uso político de dados que derrubou valor do Facebook e o colocou na mira de autoridades. G1, 20 de março de 2018. Disponível em:

https://g1.globo.com/economia/tecnologia/noticia/entenda-o-escandalo-de-uso-politico-dedados-que-derrubou-valor-do-facebook-e-o-colocou-na-mira-de-autoridades.ghtml. Acesso em 11 de ago. 2020

FEIGELSON, Bruno; SIQUEIRA, Antonio Henrique Albani. Comentários à lei geral de proteção de dados. 2019: Thomson Reuters, 2019.

FORNASIER, Mateus de Oliveira. Democracia e Tecnologias de Informação e

Comunicação: mídias sociais, bots, blockchain e inteligência artificial na opinião pública e na decisão política. Rio de Janeiro: Lumen Juris, 2020. 196 p.

FOUCAULT, Michel. Vigiar e Punir: História das Violência nas Prisões. Petrópolis: Vozes, 2004.

HOW an ex-YouTube insider investigated its secret algorithm. The Guardian, 02 de fevereiro de 2020. Disponível em: https://www.theguardian.com/technology/2018/feb/02/youtubealgorithm-election-clinton-trump-guillaume-chaslot. Acesso em 11 de agosto de 2020

IMPRENSA, Associação Brasileira de. Código de Ética dos Jornalistas Brasileiros. Disponível em: http://www.abi.org.br/institucional/legislacao/codigo-de-etica-dos-jornalistasbrasileiros/. Acesso em: 11 ago. 2020.

INSTITUTE, Oxford Internet. Junk News During the EU Parliamentary Elections: Lessons from a Seven-Language Study of Twitter and Facebook. 2019. Disponível em: https://comprop.oii.ox.ac.uk/wp-content/uploads/sites/93/2019/05/EU-Data-Memo.pdf. Acesso em: 11 ago. 2020

KARVALICS, Laszlo Z.. Information Society Dimensions. 2009. Disponível em: https://www.academia.edu/652113/Information_Society_Dimensions. Acesso em: 11 ago. 2020.

KARVALICS, Laszlo Z.. Information Society - what is it exactly? (The meaning, history and conceptual framework of an expression). 2006. Disponível em: https://www.researchgate.net/publication/237332035_Information_Society_- 
PEDROSA, Clara Bonaparte; BARACHO JUNIOR, José Alfredo de Oliveira. Algoritmos, bolha informacional e mídias sociais: desafios para as eleições na era da sociedade da informação

_what_is_it_exactly_The_meaning_history_and_conceptual_framework_of_an_expression. Acesso em: 11 ago. 2020.

MAGRANI, Eduardo. DEMOCRACIA CONECTADA: A Internet como Ferramenta de Engajamento Político-Democrático. 2014. 224 f. Tese (Doutorado) - Curso de Direito, Fgv Direito Rio, Curitiba, 2014. Disponível em:

https://bibliotecadigital.fgv.br/dspace/handle/10438/14106. Acesso em: 11 ago. 2020.

MUNDIM, Pedro Santos. Cientistas Políticos, Comunicólogos e o Papel da Mídianas Teorias da Decisão do Voto. 2010. Disponível em:

https://www.researchgate.net/publication/235891679_Cientistas_Politicos_Comunicologos_e _o_Papel_da_Midianas_Teorias_da_Decisao_do_Voto. Acesso em: 11 ago. 2020.

ORWELL, George. 1984. São Paulo: Schwarcz S.A, 2019.

PARISER, Eli. O filtro invisível: o que a internet está escondendo de você. Rio de Janeiro: Zahar, 2011.

PASQUALE, Frank. The black box society : the secret algorithms that control money and information. Cambridge, Massachusetts: Harvard University Press, 2015.

PORTO JUNIOR, Odélio. O Uso de Bots nas Eleições Brasileiras. 2018. Disponível em: https://irisbh.com.br/o-uso-de-bots-nas-eleicoes-brasileiras/. Acesso em: 11 ago. 2020.

VAIDHYANATHAN, Siva. ANTISOCIAL MEDIA: how facebook disconnects us and undermines democracy. Nova York: Oxford University Press, 2018.

VALENTINI, Rômulo Soares. Julgamento por computadores?: as novas possibilidades da juscibernética no século XXI e suas implicações para o futuro do Direito e do trabalho dos juristas. 2017. 152 f. Tese (Doutorado) - Curso de Direito, Universidade Federal de Minas Gerais, Belo Horizonte, 2017. Disponível em:

https://repositorio.ufmg.br/bitstream/1843/BUOS-

B5DPSA/1/vers_o_completa_tese_romulo_soares_valentini.pdf. Acesso em: 11 ago. 2020.

XV ENANCIB, 2014, Belo Horizonte. ALÉM DAS NUVENS: EXPANDINDO AS

FRONTEIRAS DA CIÊNCIA DA INFORMAÇÃO. Belo Horizonte: Ufmg, 2014.

Disponível em: https://ridi.ibict.br/bitstream/123456789/819/1/GT5AnaisXV.pdf. Acesso em: 11 ago. 2020. 